\title{
Temporal expression of marker transcripts: Key to successful maturation and development of mammalian oocytes
}

\author{
A Nath ${ }^{1}$, V Sharma ${ }^{3}$, N E Gade ${ }^{1}$, M D Pratheesh ${ }^{1}$, R kumar $^{2}$ and P K Dubey ${ }^{1}$ \\ 1. Division of Physiology and Climatology, 2. Division of Animal Genetics and Breeding Indian Veterinary \\ Research Institute, Izatnagar, Uttar Pradesh, India 3. Department of Biosciences and Biotechnology, \\ Banasthali University, Banasthali, Rajasthan, India \\ *Corresponding author email: amar.katiyar@gmail.com \\ Received: 20-08-2011, Accepted: 30-09-2011, Published Online: 07-12-2011 \\ doi: $10.5455 /$ vetworld.2012.121-127
}

\begin{abstract}
In vitro embryo production (IVEP) is one of the tool to gain rapid genetic improvement in livestock besides its use in conservation of endangered species. IVEP provides necessary starting material for the basic research in animal development, embryo genomics and stem cells. The success of IVEP depends upon several major factors such as quality of oocyte and sperms, type of culture medium, culture conditions etc. In vitro produced embryos differ substantially from in vivo derived embryos in the mRNA expression patterns of genes important for development. As female germplasm (oocyte) is more valuable when compared to male germplasm (sperm) because of scanty availability and relatively fixed number, it is essential to maintain quality of oocyte in IVEP. Oocyte maturation is an inevitable step towards successful IVEP as the process of maturation is still not clearly revealed, it is essential to identify temporal expression pattern of marker genes involved during maturation process for production of developmentally competent embryos. Mammalian models can provide better insight into the oocyte maturation mechanism. This review focuses on the various marker genes which are essential for successful maturation of mammalian oocyte and are key regulators in deciding the fate of oocytes for production of developmentally competent embryos.
\end{abstract}

Key Words: Oocytes, Maturation, Embryo, Developmental competence, Marker transcripts

To cite this article : Nath A, Sharma V, Gade NE, Pratheesh MD, Kumar R and Dubey PK (2012): Temporal expression of marker transcripts: Key to successful maturation and development of mammalian oocytes, Vet. World 5 (2): 121-127, doi: 10.5455/vetworld.2012.121-127

\section{I ntroduction}

In recent time much attention has been given to implement biotechnological tools in reproduction and their application in successful embryo production is obvious. Currently number of studies reported successful production of embryos in domestic animals (Bousquet et al.,1999, Luvoni, 2000, Hinrichs,2010, Paramio,2010). In vitro production of mammalian embryos has become widely accepted and is commercially applicable in live stock industry due to its advantages and flexibility. However, the efficiency of producing viable and developmentally competent embryos and the development of such embryos after embryo transfer are seeming to be inferior to that which occurs in vivo conditions.

To perform such techniques for the production of developmentally competent embryo is quite challenging even when less is known about the molecular transformation for such an important and basic aspect of reproductive biotechnology. For the production of good quality embryos and blastocyst the oocyte must have high developmental potential (Pfeffer et al., 2007), which is specifically characterized by the temporal expression of some essential oocyte marker genes viz; BMP15, GDF9, c-kit, c-Mos, MATER, ZAR1, Estradiol, Leptin, NALP9, IGFBP1, p180 etc. during the period of growth, differentiation and maturation of oocyte. Pre-implantation development studies indicates, series of morphological changes/events take place starting from germ cell development, their growth, differentiation, cumulus cells expansion, and oocyte maturation. Physiologically these are very complex events which lead to several alterations 
in cellular morphology. To understand the molecular pattern of gene expression clearly, it is necessary to know the up regulation or down regulation of these marker transcripts in time point scale during the growth, differentiation, cumulus cells expansion, oocyte maturation up to balstocyst formation and it is also essential to know role of protein and their respective functional amino acids involved in these events so their molecular characterization appears mandatory.

The molecular events controlling mammalian oocyte maturation and early embryogenesis viz; compaction, cavitation and blastocoel formation requires well orchestrated expression of genes from the maternal and/or embryonic genome (Kidder, 1992).Technical limitations and meager amount of starting material (germ cell, oocytes, different stages embryos etc.) have restricted accurate, wide spread quantitative analysis of mRNA transcript abundance in oocyte and embryos (Longergan et al., 2003; Rizos et al., 2002). Therefore knowledge of expression pattern of genes during oocyte maturation and preimplantation development is crucial for better comprehension of developmental aspect of reproductive biotechnology. There are scanty reports on molecular analysis of these important events involved in oocyte growth and maturation.

\section{Oocyte Maturation}

The mammalian oocyte maturation is defined as the reinitiating and completion of the first meiotic division, subsequent progression to metaphase II, nuclear and cytoplasmic processing, which is ultimately essential for fertilization and early embryo development. Completion of the first meiotic division takes place when oocytes undergo extensive growth through cellular interaction with the granulosa and theca cells. Asymmetric cytokinesis occurs in oocytes and first polar body containing haploid chromosome compliment is extruded. Second meiotic division follows immediately but oocytes remain arrested in metaphase II until it comes in contact with sperm. In antral follicles, the initiation of maturation in fully-grown oocytes (cumulus- oocyte- complex) is dependent on the mid-cyclic onset of the luteinizing hormone (LH) surge or the external administration of chorionic gonadotropin (CG). The ability of the oocyte to complete preimplantation development to the blastocyst stage, successful initiation and sustaining pregnancy and ultimately the birth of a healthy offspring is generally referred as developmental competence (Krisher, 2004; Sirard et al., 1992).

During follicle growth, the oocyte obtains the complement of cytoplasmic organelles and accumulates mRNAs and proteins which enable it to be fertilized and to progress through the first cleavage until embryonic genes start getting expressed. Transcriptional activity decreases as the oocyte reaches maximal size (Fair et al., 1995) and later on the oocyte depends on stored RNAs for normal function during maturation, fertilization and early embryonic development (Moor et al., 1998). After oocyte retrieval, they are surrounded by the cumulus oophorus; several layers of cumulus cells surround the oocyte in antral follicle and play an important support and regulation role in oocyte maturation (Dekel and Beers, 1980; Larsen et al., 1986).

\section{Zygotic Genome Activation: Develop- mental Competence}

Activation of zygotic genome is the first event of gene expression after fertilization which occurs within very short time intervals. This maternal zygotic transition (MZT) varies in its timing between different species. Such an oocyte embryonic transitions are sustained by gene transcripts and polypeptides produced in oocyte during oogenesis.

The activation of embryonic transcription also known as zygotic gene activation (ZGA) represents the transition from maternal to embryonic control of development. During this transition the embryo begins to synthesize its own mRNA and then protein rather than relying on that which was inherited from mother in the egg. In absence of the appropriate activation and subsequent maintenance of embryonic gene expression an embryo will simply fail to develop further for early cleavage divisions. The maternal contribution to the successful development of the zygote begins during oogenesis with the synthesis and accumulation of mRNAs and proteins in addition 
to sustaining the embryo during the early cleavage this material is also likely to contribute to development after the onset of embryonic transcription.

Developmental competence is gradually acquired during the period of oocyte growth and maturation via appropriate follicular differentiation under the control of gonadotropins (Gosden, 2002; Sutton et al., 2003; Sirard et al., 2007). Oocytes matured in vitro are known to be inferior in their developmental competence compared with in vivo matured counterparts (LeibfriedRutledge et al., 1987; van de Leemput et al., 1999; Rizos et al., 2002). In addition, significant differences have been reported in global gene expression profile between in vitro and in vivo matured human oocytes (Jones et al., 2008; Wells and Patrizio, 2008) as well as for specific candidate transcripts in bovine oocytes (Lonergan et al., 2003). The poor developmental competence of in vitro maturation (IVM) primate oocytes has been proposed to be due to failure of the timely onset of embryonic genome activation resulting from incomplete cytoplasmic maturation of these oocytes (Schramm et al., 2003). This suggests that IVM conditions may not provide the ideal conditions for oocytes and this in turn, may be related to the failure of the cumulus cells to provide the correct signaling. Therefore, it would be helpful to define marker genes that predict the developmental competence of oocytes and embryos in vitro and in vivo and that could allow the development of more appropriate maturation conditions and culture media (Calder etal., 2001).

\section{Oocyte Marker Transcripts}

The molecular mechanisms controlling meiosis, and the regulation of the cell cycle in general, was well known in 1971 with the characterization of $\mathrm{M}$ phase promoting factor (MPF, also referred to as maturation promoting factor) in mature Xenopus oocytes (Masui and Markert, 1971; Smith and Ecker,1971). MPF was originally characterized as an activity present in mature frog oocytes, which could rapidly induce nuclear maturation when injected even in minute quantities into immature oocytes. In addition to opening a new era in understanding oocyte biology, MPF was the first of the cyclin-cyclin dependent kinase (cdk) complexes to be characterized. After this a number of studies demonstrate several other molecules involved during growth differentiation and maturation of mammalian oocyte, some important of those are described here.

Transforming growth factor (TGF): The TGF super family of growth and differentiation factors has been shown to play important roles in regulating mammalian ovarian functions such as follicular development and maturation, production of steroids, and regulation of gonadotropin receptors (Knight et al., 2006, Juengel et al., 2005). TGF-b super family is comprised of secreted peptide growth factors which are critical for regulating a variety of developmental events, including cell proliferation, differentiation, matrix secretion, and apoptosis during embryogenesis and in the adult. These family members are synthesized as pre-propeptides which are processed to form mature, disulfide-linked dimers. Several TGF-b family members have been shown to get expressed in the ovary, including Mullerian inhibiting substance, inhibinA, activin bA, activin $\mathrm{bB}$, growth differentiation factor 9 (GDF9 ), bone morphogenetic protein (BMP)-6, and BMP-15, and several of these factors have been shown in vivo and/or in vitro to play important roles in regulating reproductive function (Lyons et al., 1989; McGrath et al., 1995; Dube et al., 1998). GDF-9 was first reported as expressed solely in the oocyte (McGrath et al., 1995 and McPherron et al., 1993) but was later detected not only in both female and male gonads but also in nongonadic tissues including mouse hypothalamus, human pituitary, uterus, and bone marrow and ewe pituitary (Fitzpatrick et al., 1998). Within the ovary GDF-9, BMP-6, and BMP-15 are expressed specifically in the oocyte (Lyons et al., 1989; McGrath et al., 1995; Dube et al., 1998). In particular, GDF-9 and BMP-15 mRNA are expressed specifically in the oocyte of the type $3 \mathrm{a}$ preantral follicle (small primary follicle with onelayer of granulosa cells), and expression persists in oocytes throughout all stages of folliculogenesis 
and in cumulus cell-oocyte complexes after ovulation (McGrath et al., 1995; Dube et al., 1998). It has been shown that a knockout of the GDF-9 gene leads to infertility due to a block at the type $3 b$ (primary) follicle stage, absence of thecal layer formation, and defects in oocyte meiotic competence (Elvin et al., 1999). However, the potential role of GDF-9 at later stages of folliculogenesis is unknown.

Maternal-effect genes: Maternal antigen that embryos require (MATER) and zygote arrest 1 (Zar1) are known maternal effect genes required for early development prior to zygotic genome activation (Tong et al., 2000; Wu et al., 2003). However, fundamental knowledge regarding the identification of additional oocyte-expressed proteins and their role in early embryonic development is limited. Identification and characterization of such factors will help resolve the physiological mechanism by which the oocyte drives oocyte maturation and early embryonic development, these putative factors may also function as novel objective molecular markers of oocyte and embryo competence in farm animals, the maternal contribution to successful development occurs during oogenesis with synthesis and accumulation of mRNA and proteins.

MATER was discovered as an antigen associated with ovarian autoimmunity in thymectomized mice (Tong et al., 1999). Mater human homolog was found to be expressed only in oocytes (Tong et al., 2002). Contrasting with the results in mice, human ZAR1 transcript was detected both in ovary and testis (Tong et al., 1999, 2000; Wu et al., 2003). Expression of MATER, ZAR1, GDF9, and BMP-15 was analyzed by RT-PCR during oocyte IVM and preimplantation embryo development in bovine. But it remained to be elucidated whether these maternal-effect genes were conserved in other mammalian species. In addition to the oocyte itself, ZAR1 transcript was detected in the ovary and in the testis. In human, expression is higher in the testis whereas the opposite is true in mouse (Wu et. al. 2003).
IGFs system: IGFs have been implicated in ovarian physiology because they have significant trophic and steroidogenic effects on granulosa cells in vitro (Adashi et al., 1985). Earlier it has been shown that granulosa cells produce Insulin like growth factor binding proteins (IGFBPs) in vitro, and clinical studies have raised the possibility that production of IGFBPs by granulosa cells (GC) might be instrumental in the regulation of follicular survival or maturation. The concentrations of IGFBP1 in follicular fluids with mature oocytes are found significantly higher than those in follicular fluids with intermediates and immature oocytes in human whereas IGFBP-1 demonstrates a rather obscure expression pattern in the primate ovary (Jose et al., 2002).

\section{Other Oocyte Markers:}

i) c-kit: Presence of c-kit mRNA and soluble c-kit protein first time reported in human oocytes and follicular fluid (Tanikawa et al., 1998). Ovarian c-kit, found primarily on oocytes, has autophosphorylation activity, and c-kit and KL are required for maintenance of oocyte growth in vitro.

ii) Leptin: It is the product of the obese gene (ob), and is secreted in plasma from mature adipocytes. It has been recently reported that leptin is synthesized in granulosa and cumulus cells within the follicle of the ovary, and is present in mature human oocytes, suggesting possible roles of leptin in several aspects of pre- and postovulatory follicular development (Matsuoka et al., 1999).

iii) MSY2: It is a germ-cell-specific member of the Y-box family of DNA-/RNA-binding proteins, is proposed to function as a coactivator of transcription in the nucleus and to stabilize and store maternal and paternal mRNAs in the cytoplasm. MSY2 expression is highly restricted and essentially confined to the oocytes (Yang et al., 2005).

iv) VASA: It is a DEAD box mRNA helicase involved in oocyte differentiation and germline cyst development (Styhler et al., 1998).

v) Stat-3: an oocyte marker which stains the cytoplasm of all oocytes, has critical role in early mammalian development (Antczak and Van Blerkom, 1997). 
Temporal expression of marker transcripts: Key to successful maturation and development of mammalian oocytes

\section{Conclusion}

Consistently successful and reliable oocyte maturation (both cytoplasmic and nuclear maturation) would dramatically improve the efficiency of pre-implantation embryonic development as well as fetal development. Morphological characteristics of the oocyte such as appearance of cumulus cells and cytoplasm, oocyte size and time of polar body extrusion are related to the fertilization ability of the oocytes and subsequent development into healthy and viable embryos (Juengel et al., 2005).

These morphological evaluations are not reliable enough to act as the sole criteria for the evaluation of embryo development potential in vivo after embryo transfer. Therefore more quantitative measurements such as quantitative polymerase chain reaction (Q-PCR), in-situ hybridization that measures temporal expression of marker gene during early embryonic development, immature and mature oocyte should enable more detailed picture of developmental competence than simple morphological assessments.

\section{References}

1. Adashi E.Y., Resnick C.E., Ercole D.J., Svoboda M.E.,Van Wyk J.J. (1985). Insulin like growth factors as intraovarian regulators of granulose cells. Endocrinological reviews, 6: 400-420.

2. Antczak M. and Van Blerkom J. (1997) Oocyte influences on early development: the regulatory proteins leptin and STAT3 are polarized in mouse and human oocytes and differentially distributed within the cells of the preimplantation stage embryo. Mol Hum Reprod., 3(12): 1067-86.

3. Arraztoa J.A., Monget P., Bondy C., Zhou J. (2002). Expression Patterns of Insulin-Like Growth Factor-Binding Proteins 1, 2, 3, 5, and 6 in the Mid-Cycle Monkey Ovary. The Journal of Clinical Endocrinology \& Metabolism, 87 (11): 5220-5228.

4. Bousquet $\mathrm{D}$, Twagiramungu $\mathrm{H}$, Morin $\mathrm{N}$, Brisson C, Carboneau G, Durocher J. (1999). In vitro embryo production in the cow: An effective alternative to the conventional embryo production approach. Theriogenology, 51(1): 59-70.
5. Calder M.D., Caveney A.N., Westhusin M.E., Watson A.J. (2001). Cyclooxygenase-2 and prostaglandin E2 (PGE2) receptor messenger RNAs are affected by bovine oocyte maturation time and cumulus- oocyte complex quality, and PGE2 induces moderate expansion of the bovine cumulus in vitro. Biol. Reprod., 65: 135-140.

6. Dekel N. and Beers W.H. (1980). Development of the rat oocyte in vitro: inhibition and induction of maturation in the presence or absence of the cumulus oophorus. Dev. Biol., 75: 247-254.

7. Dube J.L., Wang P., Elvin J., Lyons K.M., Celeste A.J., Matzuk M.M. (1998). The bone morphogenetic protein 15 is X-linked and expressed in oocytes. Mol. Endocrinol., 12: 1809-1817.

8. Elvin J.A., Clark A.T., Wang P., Wolfman N.M., Matzuk M.M. (1999b). Paracrine actions of growth differentiation factor-9 in the mammalian ovary. Mol. Endocrinol., 13: 1035-1048.

9. Elvin J.A., Yan C., Matzuk M.M. (2000). Oocyte-expressed TGF-b super family members in female fertility. Molecular and Cellular Endocrinology, 159: 1-5.

10. Fair T., Hyttel P., Greve T. (1995). Bovine oocyte diameter in relation to maturational competence and transcriptional activity. Mol. Reprod. Dev., 42: 437-442.

11. Gosden R.G. (2002). Oogenesis as a foundation for embryogenesis. Mol. Cell. Endocrinol., 186: 149-153.

12. Hinrichs K. (2010). In Vitro Production of Equine Embryos: State of the art. Reprod. in Domestic Animals, 45 (2): 3-8.

13. Jones G.M., Cram D.S., Song B., Magli M.C., Gianaroli L., Lacham-Kaplan O., Findlay J.K., Jenkin G., Trounson A.O. (2008). Gene expression profiling of human oocytes following in vivo or in vitro maturation. Hum. Reprod. 23: 1138-1144.

14. Juengel J.L. and McNatty K.P. (2005). The role of proteins of the transforming growth factor-superfamily in the intraovarian regulation of follicular development. Hum. Reprod. Update 11: 143-160.

15. Kidder G.M. 1992. The genetic program for preimplantation development. Dev Genet 13: 319-325.

16. Knight P.G. and Glister C. (2006). TGF-superfamily members and ovarian follicle development. Reproduction 132: 191-206. 
17. Krisher R.L. (2004). The effect of oocyte quality on development. J. Anim. Sci., 82 (Suppl. E): E14-E23.

18. Larsen W.J., Wert S.E., Brunner G.D. (1986). A dramatic loss of cumulus cell gap junctions is correlated with germinal vesicle breakdown in rat oocytes. Dev. Biol., 113: 517-521.

19. Leibfried-Rutledge M.L., Critser E.S., Eyestone W.H., Northey D.L., First N.L. (1987). Development potential of bovine Oocytes matured in vitro or in vivo. Biol. Reprod., 36: 376-383.

20. Lonergan P., Gutiérrez-Adan A., Rizos D., Pintado B., de la Fuente J., Boland M.P. (2003). Relative messenger RNA abundance in bovine oocytes collected in vitro or in vivo before and 20 $\mathrm{h}$ after the preovulatory luteinizing hormone surge. Mol. Reprod. Dev., 66: 297-305.

21. Lonergan P., Rizos D., Gutiérrez-Adán A., Moreira P.M., Pintado B., de la Fuente J. Boland M.P. (2003). Temporal Divergence in the Pattern of Messenger RNA Expression in Bovine Embryos Cultured from the Zygote to Blastocyst Stage In Vitro or In Vivo. Biol. of Reprod., 69 (4): 1424-1431.

22. Luvoni G.C. (2000). Current progress on assisted reproduction in dogs and cats: in vitro embryo production. Reprod. Nutr. Dev., 40(5): 505-12.

23. Lyons K.M., Pelton R.W., Hogan B.L. (1989). Patterns of expression of murine $\mathrm{Vgr}-1$ and BMP-2a RNA suggest that transforming growth factor-beta-like genes coordinately regulate aspects of embryonic development. Genes Dev., 3(11): 1657-68.

24. Masui Y. and Markert C.L. (1971). Cytoplasmic control of nuclear behavior during meiotic maturation of frog oocytes. J Exp Zool. 177(2): 129-145.

25. Matsuoka T., Tahara M., Yokoi T., Masumoto N., Takeda T., Yamaguchi M., Tasaka K., Kurachi H., Murata Y. (1999). Tyrosine phosphorylation of STAT3 by leptin through leptin receptor in mouse metaphase 2 stage oocyte. Biochem Biophys Res Commun., 256(3):480-4.

26. McGrath S.A., Esquela A.F., Lee S.J. (1995). Oocyte-specific expression of growth: differentiation factor-9. Mol. Endocrinol., 9: 131-136.

27. McPherron A.C. and Lee S.J. (1993). GDF-3 and GDF-9: two new members of the transforming growth factor-beta super family containing a novel pattern of cysteines. J. Biol. Chem., 268: 3444-3449.
28. Moor R.M., Dai Y., Lee C., Fulka J. Jr. (1998). Oocyte maturation and embryonic failure. Hum. Reprod. Update, 4: 223-236.

29. Paramio M.T. (2010). In vivo and in vitro embryo production in goats. Small Ruminant Research, 89 144-148.

30. Pfeffer P.L., Sisco B., Donnison M., Somers J., Smith C., (2007). Isolation of genes associated with developmental competency of bovine oocytes. Theriogenology, 68: S84-S90.

31. Rizos D., Lonergan P., Ward F., Duffy P., Boland M. P. (2002). Consequences of bovine oocyte maturation, fertilization or early embryo development in vitro versus in vivo: implications for blastocyst yield and blastocyst quality. Mol. Reprod.Dev., 61:234-248.

32. Schramm R.D., Paprocki A.M., VandeVoort C.A. (2003). Causes of developmental failure of in-vitro matured rhesus monkey oocytes: impairments in embryonic genome activation. Hum. Reprod., 18: 826-833.

33. Sirard M.A., Coenen K., Bilodeau S. (1992). Effect of fresh or cultured follicular fractions on meiotic resumption in bovine Oocytes. Theriogenology, 37: 39-57.

34. Sirard M.A., Desrosier S., Assidi M. (2007). In vivo and in vitro effects of FSH on oocyte maturation and developmental competence. Theriogenology, 68: S71-S76.

35. Smith L.D. and Ecker R.E. (1971). The interaction of steroids with Rana pipiens Oocytes in the induction of maturation. Dev. Biol., 25(2): 232-247.

36. Styhler S., Nakamura A., Swan A., Suter B., Lasko P. (1998). vasa is required for GURKEN accumulation in the oocyte, and is involved in oocyte differentiation and germline cyst development. Development, 125(9):1569-78.

37. Sutton M.L., Gilchrist R.B., Thompson J.G. (2003). Effects of in-vivo and in-vitro environments on the metabolism of the cumulus-oocyte complex and its influence on oocyte developmental capacity. Hum. Reprod. Update, 9: 35-48.

38. Tanikawa M., Harada T., Mitsunari M., Onohara Y., Iwabe T., Terakawa N. (1998).Expression of c-kit messenger ribonucleic acid in human oocyte and presence of soluble c-kit in follicular fluid. J Clin Endocrinol Metab. ;83(4):1239-42.

39. Tong Z.B. and Nelson L.M. (1999). A mouse gene encoding an oocyte antigen associated with autoimmune premature ovarian failure. Endocrinology, 140: 3720-3726.

40. Tong Z.B., Bondy C.A., Zhou J., Nelson 
Temporal expression of marker transcripts: Key to successful maturation and development of mammalian oocytes

L.M. (2002). A human homologue of mouse Mater, an aternal effect gene essential for early embryonic development. Hum. Reprod., 17: 903-911.

41. Tong Z.B., Gold L., Pfeifer K.E., Dorward H., Lee E., Bondy C.A., Dean J., Nelson L.M. (2000). Mater, A maternal effect gene required for early embryonic development in mice. Nat. Genet., 26: 267-268.

42. Van de Leemput E.E., Vos P.L., Zeinstra E.C., Bevers M.M., Van der Weijden G.C. Dieleman, S.J.(1999). Improved in vitro embryo development using in vivo matured oocytes from heifer's superiovulated with a controlled preovulatory LH surge. Theriogenology, 52: 335-349.
43. Wells D. and Patrizio P. (2008). Gene expression profiling of human Oocytes at different maturational stages and after in vitro maturation. Am.J.Obstet. Gynecol. 198: 455-455.

44. Wu X., Viveiros M.M., Eppig J.J., Bai Y., Fitzpatrick S.L., Matzuk M.M. (2003). Zygote arrest 1 (Zar1) is a novel maternal-effect gene critical for the oocyte-to-embryo transition. Nat. Genet. 33:187-191.

45. Yang J., Medvedev S., Yu J., Tang L.C., Agno J.E., Matzuk M.M., Schultz R.M., Hecht N.B. (2005). Absence of the DNA-/RNA-binding protein MSY2 results in male and female infertility. Proc Natl Acad Sci U S A.,102(16): 5755-60. 